\title{
RELATIONSHIP BETWEEN COFFEE CONSUMPTION, SLEEP DURATION AND SMOKING STATUS WITH ELASTOGRAPHIC PARAMETERS OF LIVER STEATOSIS AND FIBROSIS; CONTROLLED ATTENUATION PARAMETER AND LIVER STIFFNESS MEASUREMENTS
}

\author{
Ivana Mikolasevic $^{1}$, Viktor Domislovic ${ }^{2}$, Tajana Filipec Kanizaj ${ }^{2}$, Delfa Radic-Kristo ${ }^{2}$, \\ Zeljko Krznaric ${ }^{2}$, Toni Juric ${ }^{3}$, Mia Klapan ${ }^{3}$, Nadija Skenderevic ${ }^{2}$, Andjela Lukic ${ }^{3}$, and \\ Davor Stimac ${ }^{2}$ \\ ${ }^{1}$ UHC Rijeka \\ ${ }^{2}$ Affiliation not available \\ ${ }^{3}$ School of Medicine Rijeka
}

July 22,2020

\begin{abstract}
Aim: our aim was to explore the association between life habits and the controlled attenuation parameter (CAP) and liver stiffness measurements (LSM) as the surrogate markers of liver steatosis and fibrosis in a large cohort of nonalcoholic fatty liver disease (NAFLD) patients. Methods: In this prospective, cross-sectional study we had analyzed 1998 patients with diagnosed NAFLD. Sleeping duration was categorized in three groups: short (S) $(<6 \mathrm{~h})$, moderate $(\mathrm{M})(6-8 \mathrm{~h})$ and long $(\mathrm{L})(>8 \mathrm{~h})$ sleep duration. Coffee drinking was categorized into no (0), moderate (1-2) and frequent ([?]3) consumption (in cups/day). Smoking was categorized as yes vs. no. Results: Frequent coffee consumers had the lowest prevalence of obesity, hypertension, dyslipidemia, and diabetes. Furthermore, coffee non-consumers had highest values of hepatic enzymes, CAP and LSM. Moderate sleep duration was associated with lower values of CAP and LSM. Coffee consumption was associated with lower CAP in all the multivariate models (CAP unadjusted and model 1,2 and 3), with largest effect in most frequent coffee consumers ([?]3, model 3). Also, most frequent coffee consumers were associated with lower LSM in unadjusted model, model 1 and 2 , while this was not the case for model 3 and those who consumed 1-2 cups of coffee per day. Reduced sleeping was confirmed as risk factor for elevated CAP in most of the models (unadjusted and model 1 and 2). Also, negative association of LSM was also confirmed in unadjusted model and model 2. Patients which slept 6-8 hours per day were mostly associated with lower CAP and LSM. Smoking did not affect CAP or LSM values. Conclusion: Coffee consumption has beneficial effect on CAP and LSM and this effect is dose dependent since and independent of a variety of relevant confounders. We have shown that moderate sleep duration has also beneficial effect on CAP and LSM.
\end{abstract}

\section{What is known?}

Over the last decade non-alcoholic fatty liver disease (NAFLD) has become the most common chronic liver disease in Western world. There are still no approved therapy for NAFLD treatment. Some authors have published data about beneficial effects of coffee consumption in diabetes mellitus, while some other reported its usefulness in the context of fibrosis, cirrhosis, and hepatocellular carcinoma in chronic hepatitis C infected patients. Some reports had shown that short sleep duration was associated with NAFLD prevalence, while some other studies reported that that long sleep duration related to incident NAFLD. Finally, smoking is an 
acknowledged risk factor for developing metabolic syndrome, which is risk factor for NAFLD development.

\section{What is new?}

We have shown that coffee consumption has beneficial effect on CAP and LSM and that effect is dose dependent since the positive effect of coffee consumption was the most pronounced in the frequent users. This effect was independent of a variety of relevant confounders. Additionally, we have shown that optimal sleep duration (6-8 hours per day) has also beneficial effect on CAP and LSM. Since sleep insufficiency is a common problem today and since coffee is a widely accessible and relatively low-cost beverage, present study can have considerable public health implications for the relationships between lifestyle factors and NAFLD epidemic

\section{INTRODUCTION}

Over the last decade non-alcoholic fatty liver disease (NAFLD) has become the most common chronic liver disease (CLD) in Western world. This liver disease is a clinical syndrome which consists of several liver disorders. It is defined by existence of steatosis in at least $5 \%$ of hepatocytes with no history of alcohol consumption or evidence of other CLD. The clinical-histologic phenotype of the disorder extends from benign non-alcoholic fatty liver (NAFL) to more severe non-alcoholic steatohepatitis (NASH). NASH is more progressive form that can lead to fibrosis and cirrhosis which consequently lead to liver transplantation or progress to hepatocellular carcinoma (HCC) (1-4) Today, NAFLD is acknowledged as a liver manifestation of metabolic syndrome (MetS). With NAFLD being part of MetS, it can be closely associated with unhealthy lifestyle. Studies have shown that changes in unhealthy lifestyle improve transaminase levels and NAFLD (5).

One of the most popular beverages in the world is coffee. Inarguably, drinking coffee is a cultural phenomenon with billions of cups consumed worldwide. In recent years, a lot of interest has been tempted in the overall beneficial effects regarding the coffee consumption in reducing total and cause specific morbidity and mortality. Coffee seems to benefit health in general, especially liver health (6-10). Some authors have published data about beneficial effects of coffee consumption in diabetes mellitus (7), while some other reported its usefulness in the context of fibrosis, cirrhosis, and HCC in chronic hepatitis C infected patients (8). Due to epidemic increase of type 2 diabetes mellitus (T2DM), obesity and MetS, around $25 \%$ of population has fatty liver disease. NAFLD is not only important due to liver-related complications (i.e. cirrhosis and HCC) but also it is important in the context of multisystem disease that is associated with cardiovascular diseases, chronic kidney disease and T2DM, as well as to some other chronic diseases. Therefore, the beneficial effect of coffee consumption could be of great clinical interest because coffee is easily available. Although according to meta-analysis by Shen $\mathrm{H}$ et al (9) about the beneficial effect of coffee consumption on progression of liver disease, its effect in NAFLD population is not unequivocally clear.

Poor health outcomes are also associated with inadequate sleep. Insomnia and short sleep duration have been linked with obesity, diabetes, hypertension, cardiovascular diseases, and depression. Mechanism of it lies in irregular habits in exercise and diet, decreased leptin, and modulation of hormones of hypothalamicpituitary-adrenal system $(11,12)$. Some reports had shown that short sleep duration was associated with NAFLD prevalence, while some other studies reported that that long sleep duration related to incident NAFLD (11-13). Thus, the relationship between NAFLD and sleep duration is still poorly defined.

Finally, cigarette smoking is an unhealthy habit that is associated with many diseases on numerous organs. This habit damages the antioxidant system which can have repercussions on numerous organs. Smoking is an acknowledged risk factor for developing MetS, which is risk factor for NAFLD development (16-18). It has been reported that smoking can increase the risk for fibrosis and cirrhosis in patients with viral hepatitis, but only a few studies have investigated the relationship between smoking and NAFLD (16-18).

According to this observations, our aim was to explore the association between coffee consumption, sleep duration and smoking status and the controlled attenuation parameter (CAP) and liver stiffness measurements (LSM) as the surrogate markers of liver steatosis and fibrosis in a large cohort of NAFLD patients in 
Mediterranean parts of Croatia.

\section{MATERIALS AND METHODS}

\section{Subjects}

In this prospective, cross-sectional study we had analysed 2456 consecutive adult patients age [?]18 years with diagnosed NAFLD at Clinical Hospital Centre (CHC) Rijeka, University of Rijeka, Croatia. For the purpose of this study, all patients visiting the Gastroenterology department of CHC Rijeka between April 2013 and May 2019 were analysed and underwent anthropometric assessment, blood sampling, abdominal ultrasound (US) and transiet elastography (TE) with CAP. Exclusion criteria were presence of other CLD, active malignancy, celiac disease, secondary causes of fatty liver like drugs (amiodaron, tamoxifen), congestive heart failure (including valvular heart disease), alcohol consumption of more than $20 \mathrm{~g}$ per day for men and more than $10 \mathrm{~g}$ per day for women, those with more than 3 times the normal serum alanine aminotransferase (ALT), aspartate aminotransferase (AST) or $\gamma$-glutamyltransferase (GGT) levels, TE failure and pregnancy. Those with incomplete information on sleep duration, coffee consumption and smoking status were not a part of this study. With this exclusion criteria, 1998 adult patients with NAFLD were included in the final analysis (Figure 1). The study was approved by the Institutional Ethics Committee and was conducted in line with the Declaration of Helsinki. All patients signed written informed consent.

\section{Definition of NAFLD}

NAFLD was diagnosed in patients a) with one or more MetS component (T2DM, hypertension, obesity and/or dyslipidaemia) b) those with altered or normal liver enzymes c) those with a "bright" liver as seen on the abdominal ultrasound - Philips Affiniti (PC Best, Nederland) d) those with excluded secondary causes of CLD e) based on the transient elastography (TE) with CAP findings.

\section{Clinical assessment}

A detailed clinical assessment was performed in each patient. Information on medical history, past and current drugs and alcohol consumption were collected. In this study, we analyzed alcohol consumption by asking the patient about the type and amount of alcohol consumption per day during the prior year, then estimating the mean alcohol intake per day. Anthropometric assessments were performed by well-trained nurses and included body mass index (BMI) and waist circumference (WC). Obesity was defined in patients that had BMI [?] $30 \mathrm{~kg} / \mathrm{m}^{2}$, and central obesity as WC $>94 \mathrm{~cm}$ for male and $>80 \mathrm{~cm}$ for female. Hypertension was defined if there was positive medical history or if the patient was taking anti-hypertensive drugs or if the average blood pressure after three repeated measures was [?]140/90 $\mathrm{mmHg}$. Dyslipidemia was defined as positive medical history, using of lipid-lowering drugs, or if the serum total cholesterol level was [?]5.2 $\mathrm{mmol} / \mathrm{L}$, serum triglyceride (TG) level [?]1.7 mmol/L, serum high-density lipoprotein (HDL) cholesterol level $<1.0 \mathrm{mmol} / \mathrm{L}$ for male or $<1.3 \mathrm{mmol} / \mathrm{L}$ for female, or serum low-density lipoprotein (LDL) cholesterol level [?]3.4 mmol/L. The MetS was defined according to the International Diabetes Federation criteria that are including central obesity (waist circumference $>80 \mathrm{~cm}$ for women and $>94 \mathrm{~cm}$ for men) plus at least two of the following risk abnormalities: blood pressure [?]130/85 $\mathrm{mmHg}$ or drug treatment; previously diagnosed type 2 diabetes, or drug treatment or a fasting plasma glucose level [?]5.6 mmol/L; triglyceride levels $>1.7$ $\mathrm{mmol} / \mathrm{L}$ and/or HDL-cholesterol $<1.03 \mathrm{mmol} / \mathrm{L}$ for men and $<1.29 \mathrm{mmol} / \mathrm{L}$ for women or drug treatment. An extensive laboratory characteristic was analyzed for each patient including and all necessary laboratory tests for exclusion of other CLD. Fasting blood samples for analyzing laboratory parameters were taken in the morning hours after overnight fasting at the day of TE and US examinations. Sleeping duration, coffee consumption and smoking were recorded using quantitate questionnaire. Sleeping duration was categorized in three groups: short $(\mathrm{S})(<6 \mathrm{~h})$, moderate $(\mathrm{M})(6-8 \mathrm{~h})$ and long $(\mathrm{L})(>8 \mathrm{~h})$ sleep duration. Each patient was asked if he had drunk coffee in the previous year, and how many cups per day. Therefore, coffee drinking was categorized into no (0), moderate (1-2) and frequent ([?]3) consumption (in cups/day, one cup equals $150 \mathrm{~g})$. Smoking was categorized as yes vs. no. Those patients who reported as smoking at least sporadically during the last two year were defined as smokers. On the other hand, those who reported as having stopped smoking at least two year before their enrolment in our study and those who had not smoked during their 
life were defined as non-smokers.

\section{Transient elastography and liver ultrasound}

LSM and CAP were obtained by using Fibroscan $\AA 502$ (Echosens, Paris, France) by a single operator who had performed more than 2.000 examinations before the start of this study. In each patient a minimum of 10 seral measurements were done using the M- or the XL probe according to the instructions. The examination was defined as successful if there was [?]10 valid measurements with interquartile range (IQR)-to-median ratio of LSM was [?]0.3. Liver steatosis was defined by the mean CAP values of [?] $238 \mathrm{~dB} / \mathrm{m}$ (19). According to earlier published data, significant liver fibrosis ([?]F2) was defined as an LSM [?]7kPa and advanced fibrosis ([?]F3) if LSM was [?]9.6 $\mathrm{kPa}$ using the M probe or [?]9.3 kPa using the XL probe. On the other hand, cirrhosis was considered if the LSM was [?] $11.5 \mathrm{kPa}$ using the M probe or [?] $11.0 \mathrm{kPa}$ using the XL probe $(20,21)$. Abdominal US was carried out by a certified and experienced gastroenterologist on Philips Affiniti (PC Best, Nederland). Diagnosis of steatosis was determined dichotomously according to the protocol of Hamaguchi et al (22), as presence or absence of a hyper-echogenic liver parenchyma.

\section{Statistical analysis}

Categorical variables are shown as percentages and continuous variables as medians with interquartile range (25th and 75th percentiles) due to the distribution. Distribution relationship between categorical variables values was tested using $\chi 2$-test, and if necessary, Fisher's exact test. To analyze the difference between three continuous variables Kruskal-Wallis test with post hoc Mann-Whitney U-test for non-parametric analysis was used, while the difference between two continuous variables was tested using Mann-Whitney U-test. Multivariable logistical regression analyses were conducted to identify patient characteristics independently associated with coffee consumption, sleeping and smoking. Those factors with a $\mathrm{p}$ value $<0.05$ in the univariate analyses were selected as candidate variables for backward multivariable logistical regressions. Finally, focused analysis of coffee consumption, sleeping and smoking association with CAP and LSM was performed in unadjusted and three adjusted models (Model 1,2 and 3) to determine the consistency or change of influence among variables. All the statistical analyses were performed using SPSS V.22.0 (SPSS Inc, Chicago, Illinois, USA). Statistical tests were two-tailed and significance was set at 0.05.

\section{RESULTS}

Demographic and laboratory characteristics of study subjects by coffee consumption, sleeping hours and smoking status

Average age of patients across different categories of coffee consumption, sleeping and smoking status ranged from 54 to 60 years with approximately half of the patients being female gender. Female patients consumed coffee more frequent and were smokers. Overall average BMI ranged from 27.2 to $30.8 \mathrm{~kg} / \mathrm{m}^{2}$, being the lowest in most frequent coffee consumers. This was also the case for hypertension, dyslipidemia and DM where the proportions were lowest also in most frequent coffee consumers. Furthermore, coffee non-consumers had highest values of hepatic enzymes, CAP and LSM. Patients who slept 6-8 hours per day had lowest values of CAP and LSM, and lowest proportion of T2DM and dyslipidemia. There was no difference in LSM and CAP when comparing smokers and non-smokers. All of the characteristics are shown in Table 1. CAP and LSM values according to the categories of coffee consumption, sleeping and smoking status are shown in Figure 2 and 3.

\section{Association of coffee consumption with demographical data, laboratory values and elastographic parameters}

In univariate analysis most frequent coffee consumers ([?]3 cups per day) were negatively associated with BMI, WC, DM, AST, ALT, GGT, HOMA-IR, CAP and LSM, while positive association was obtained for female gender and HDL. In multivariate analysis significant negative association was obtained in obese patients, WC, AST, ALT and CAP. Patients which consumed 1-2 cups per day were in multivariate model negatively associated with WC and CAP (Table 2).

Association of sleeping with demographical data, laboratory values and elastographic parameters 
In univariate analysis reduced sleeping ( $<6$ hours) was positively associated with BMI, DM, glucose, vitamin $\mathrm{D}$ and CAP, while negatively associated with LSM. In multivariate analysis significant positive association was obtained for CAP and vitamin D. Patients which slept 6-8 hours per day compared to those who slept [?]8 hours per day were in multivariate analysis positively associated with ALT and vitamin D, while negatively with DM (Table 3).

Association of smoking status with demographical data, laboratory values and elastography parameters LSM and $C A P$

In univariate analysis smokers were positively associated with female gender, GGT, cholesterol and negatively with age. In multivariate model only age and gender were independently associated with smoking status. (Table 4).

\section{Association of coffee consumption, sleeping and smoking status with CAP and LSM}

Coffee consumption was associated with lower CAP in all of the multivariate models (CAP unadjusted and model 1,2 and 3), with largest effect in most frequent coffee consumers ([?]3, model 3). Also, most frequent coffee consumers were associated with lower LSM in unadjusted model, model 1 and 2, while this was not the case for model 3 and those who consumed 1-2 cups of coffee per day. Reduced sleeping was confirmed as risk factor for elevated CAP in most of the models (unadjusted and model 1 and 2). Also, negative association of LSM was also confirmed in unadjusted model and model 2. Patients which slept 6-8 hours per day were mostly associated with lower CAP and LSM. Smoking did not affect CAP or LSM values.

\section{DISCUSSION}

Nowadays, we know that T2DM, obesity, hypertension, and dyslipidemia as the MetS components are the main risk factors for NAFLD. On the other hand, NAFLD development is also influenced by multiple features, such as demographic, genetic, and environmental determinants (23). Therefore, the investigation of the possible influence of other putative factors is becoming in interest of clinicians who manage NAFLD patients. To the best of our knowledge, there are limited data about the association among coffee consumption and sleep duration with elastographic parameters of liver steatosis and fibrosis; CAP and LSM in population of patients with NAFLD. In this large cohort of NAFLD patients we have investigated the association between coffee consumption, sleep duration and smoking status with the CAP and LSM as a surrogate marker of steatosis and fibrosis.

According to the epidemiological study by Nordestgaard AT, et al (24) that had included 93.179 individuals, high coffee intake was associated with lower risk of T2DM, obesity and MetS. Similar data were reported by the meta-analysis from 2016. that had analyzed 11 reports including 13 studies with a total of 159.805 participants. Coffee consumption was associated with a low risk of MetS (25). Furthermore, Xie C, et al (26) in their meta-analysis that was published two years ago had reported that consumption of coffee was inversely associated with the risk of hypertension in a dose-response manner. In the line with this data, in our study frequent coffee consumers (3[?]caps per day) had the lowest incidence of all MetS components; dyslipidemia, obesity, T2DM and hypertension. Interestingly, female patients consumed coffee more frequent. In multivariate analysis moderate and frequent coffee consumption showed significant negative association with obesity, and this effect was and more pronounced for frequent coffee consumption. Additionally, earlier data have been reported that coffee consumption has been associated with lower liver enzyme levels; ALT, GGT, AST. A first report about the beneficial effect of coffee consumption on GGT was published in 1986 (27). Until then, many authors have demonstrated a similar effect on AST, ALT as well as GGT levels (28-31). Accordingly, based on our results, all three liver enzymes (AST, ALT, GGT) were the lowest in the subgroup of frequent coffee consumers. In multivariate analysis, moderate coffee consumption did not to have a significant effect on liver enzymes, while frequent coffee consumption was significant predictor of lower ALT and GGT. These results suggest that the beneficial effect of coffee consumption on liver enzymes is dose dependent. Regarding the earlier data about beneficial effect of coffee consumption on MetS and its individual components and regarding the fact that NAFLD is strongly associated with MetS it is not surprising that many authors had also showed beneficial effect of coffee in the context of NAFLD. 
For example, study by Birerdinc A, et al (32) has shown that caffeine intake is independently associated with a lower risk for NAFLD. In this study NAFLD was defined by elevated serum aminotransferases. Similar results were reported by the study that was published 10 years ago and, in this study, NAFLD was detected based on the US (33). More convincing data about this association comes from the Molloy JW, et al (34). However, in their study NAFLD was defined by liver biopsy. In Rotterdam study from 2017, liver steatosis was defined by US while fibrosis was defined by LSM (35). According to their results, frequent coffee consumption was inversely related with liver stiffness but not steatosis (35). On the contrary, Veronese N, et al (6) reported that the consumption of coffee or an increased consumption of coffee were not associated with the presence of mild, moderate or severe liver steatosis in NAFD patients in a large study of 2819 participants from the Mediterranean Area. NAFLD was defined by the US. Hodge A, et al (36) have investigated the association between coffee intake and liver stiffness in patients with NAFLD ( $\mathrm{n}=155)$, hepatitis B $(\mathrm{n}=485)$ and $\mathrm{C}(\mathrm{n}=378)$. They have found that LSM was lower in those patients who drank 2 or more cups of coffee per day (36). Only in 105 NAFLD patients a CAP measurement was performed (36). Authors did not find any correlation between the coffee consumption and CAP values (36). According to our best knowledge, this is only study that was investigated the influence of coffee consumption in relation to the CAP measurements. In our study we had performed LSM and CAP measurements in relatively large population of NAFLD patients. According to our results, coffee non-consumers had highest values of CAP and LSM. Moreover, in multivariate analysis, moderate and frequent coffee consumption showed a significant negative effect on CAP values, but none on the LSM measurements. The more convincing data in our study come from the results that coffee consumption was associated with lower CAP in all of the multivariate models, with largest effect in most frequent coffee consumers ([?]3, model 3). Also, most frequent coffee consumers were associated with lower LSM in most of the models while this was not the case for those who consumed 1-2 cups of coffee per day. These results are in the line with some clinical studies and some pre-clinical study. According to the preclinical studies, caffeine has a few beneficial effects in the context of NAFLD. Firstly, caffeine has antioxidant properties. Secondly, it seems to be able to promote the blockade of transforming growth factor $\beta$ expression and of its downstream inductor connective tissue growth factor. Thirdly, caffeine can inhibit hepatic stellate cells and subsequently counteracted fibrogenesis and finally as it was mentioned earlier it has beneficial effect on MetS development which is closely related to NAFLD. Furthermore, coffee contain and polyphenols. It has been suggested that polyphenols have hepatoprotective effects independent of caffeine. Preclinical studies showed that coffee-polyphenols attenuate obesity-related lipid accumulation in the liver additionally with their antioxidant properties $(6,35,31,37,38,39,40)$.

In the second part of our study we had investigated the association among sleep duration and CAP and LSM values. Patients who slept 6-8 hours per day had lowest values of CAP and LSM, while those who slept $<6$ hours per day had the highest values of CAP, and those with $>8$ hours highest LSM values. In multivariate analysis, sleeping duration less than 6 hours per day was associated with higher CAP values. Reduced sleeping was confirmed as risk factor for elevated CAP in most of the models, while it has been show that short sleep duration could have beneficial effect in the context of LSM, in unadjusted model and model adjusted for age, gender and BMI. This effect is weak, and moreover, there are still several sleeping factors that could be taken into to achieve unbiased results such as sleep disturbance, efficiency, quality etc. Further studies are needed regarding sleeping factors and LSM. Additionally, patients which slept 6-8 hours per day were mostly associated with lower CAP and LSM values independent of a variety of relevant confounders including age, gender, BMI. We can explain these findings by some earlier data. Obesity, T2DM and insulin resistance, all of which are of importance in the development of NAFLD were more frequent in those who slept less than 6 hours per day, and their incidence was the lowest in those who slept 6-8 hours per day. In multivariate analysis, those who slept 6-8 hours per day had significantly lower incidence of T2DM. Interestingly, patients who slept 6-8 hours per day had the highest values of vitamin $\mathrm{D}$, and we know that vitamin $\mathrm{D}$ is also involved in pathogenesis of NAFLD. In multivariate analysis vitamin D was positively associated with sleeping duration of 6-8 hours per day and with sleep duration of less than 6 hours per day, although this effect was low, thus further studies regarding the association among vitamin D and sleeping duration, especially in the context of NAFLD are needing. According to other studies, patients with a short sleep duration have higher levels of tumor necrosis factor-alpha and 
interleukin-6, an inflammatory cytokine that are involved in the pathogenesis of NAFLD $(11,41,42)$. Sleep deprivation could influence the hypothalamo-pituitary-adrenal axis activity. That is important because some data showed that this could cause subclinical hypercortisolism and exacerbate NAFLD. Also, it has been showed that lifestyle is associated with sleep duration and earlier data reported that participants with a short sleep duration had dinner at late-night which was a risk of hyperglycemia or obesity. It is believed that short sleep duration is a risk factor for T2DM, obesity, insulin resistance and MetS development, that are all risk factors for NAFLD development $(11,43,44,45)$. Taking together all this data, short sleep duration could be a risk factor for NAFLD development. Our results are in line with some other clinical studies. For example, Okamura T, et al (11) had showed that short sleep duration was a risk factor for incident NAFLD. Similar results were reported by Peng K, et al (46). In their study, short sleep duration and longer daytime napping were associated with an increased risk of prevalent NAFLD. In both studies NAFLD was diagnosed with US. However, abdominal US is good method for those NAFLD patients who have a percentage of liver steatosis of more than $30 \%$. It is known that US has a low sensitivity for the detection of mild steatosis and is more operator dependent. In contrast to US, TE with CAP can detect a mild steatosis when approximately $10 \%$ of hepatocytes have fatty infiltration. Thus, studies using US are more likely to underestimate the true prevalence of NAFLD $(19,47)$. According to our best knowledge, there are no studies that were using CAP for steatosis detection in relation to the sleep duration. In the study by Marin-Alejandre BA, et al (15) NAFLD was diagnosed by transaminases and liver stiffness was determined by Acoustic Radiation Force Impulse elastography (ARFI). In this study, the authors had found the association of sleep characteristics with the development and progression of NAFLD (15). In our study we did not analyzed other sleep characteristics such as sleep disturbance, sleep efficiency and sleep quality, thus further studies should analyze more comprehensively the association between sleep characteristics and NAFLD are needed.

Finally, the relationship between smoking status and NAFLD remains controversial. Recent study had reported that current smoking, pack-years, and urinary cotinine levels were associated with the risk of incident NAFLD (48). Ou H,et al (49) analyzed 225 NAFLD patients. NAFLD was diagnosed by TE. Authors showed that smoking was associated with liver fibrosis (defined by LSM) among the patients with NAFLD. The sample size of this study is relatively small. In our study with a relatively large population of patients with TE defined NAFLD we did not find any association among smoking status and CAP and LSM values as a surrogate marker of steatosis and fibrosis. Further studies are warranted.

This study has some limitations. Firstly, NAFLD was defined by TE with CAP, and we did not use liver biopsy for detection of it. Although liver biopsy is the gold standard for NAFLD diagnosis, CAP and LSM are the best validated noninvasive marker for steatosis and fibrosis detection. And according to recent study, CAP and LSM have good correlation with liver histology (50). Secondly, this was a prospective, cross-sectional study, therefore, we are not able to draw conclusions regarding the cause-effect relationship of coffee consumption, sleep duration and smoking status in relation to the CAP and LSM. Thirdly, in our study we investigated the sleep duration and we did not analyzed other sleep characteristics such as sleep disturbance, sleep efficiency and sleep quality, thus further studies should analyze more comprehensively the association between sleep characteristics and CAP and LSM are needed. Thirdly, short sleep duration is possible associated with increased energy intake which is a risk factor for NAFLD. In this study, we did not have the information's regarding the dietary intake and thus we did not investigate the association between sleep duration and dietary intake.

However, the current study has the strength of a relatively large sample size and the use of one of the best non-invasive methods for liver steatosis and fibrosis detection and quantification. According to our best knowledge, there are limited data about the association of coffee consumption and sleep duration in relation to the CAP and LSM. We have shown that coffee consumption has beneficial effect on CAP and LSM and that effect is dose dependent since the positive effect of coffee consumption was the most pronounced in the frequent users. This effect was independent of a variety of relevant confounders. Additionally, we have shown that optimal sleep duration (6-8 hours per day) has also beneficial effect on CAP and LSM. Since sleep insufficiency is a common problem today and since coffee is a widely accessible and relatively low- 
cost beverage, present study can have considerable public health implications for the relationships between lifestyle factors and NAFLD epidemic. This is important regarding the fact that as our population ages, the prevalence of NAFLD will increase and due to growing epidemic of obesity, T2DM and MetS. Because of absence of prospective data, we can only conclude that there is positive association between better liver health and coffee consuming as well as between better liver health and sleep duration between 6-8 hours. Otherwise speaking, more prospective studies needs to be done before we can conclude that coffee consuming, and sleep duration are responsible for prevention and better outcome in patients with NAFLD.

\section{REFERENCE}

1. Cobbina E, Akhlaghi F, Non-alcoholic fatty liver disease (NAFLD) - pathogenesis, classification, and effect on drug metabolizing enzymes and transporter. Drug Metab Rev. 2017; 49: 197-211.

2. Younossi ZM, Koenig AB, Abdelatif D, Fazel Y, Henry L, Wymer M. Global epidemiology of nonalcoholic fatty liver disease-Meta-analytic assessment of prevalence, incidence, and outcomes. Hepatology. 2016; 64: 73-84.

3. Boddi M, Tarquini R, Chiostri M, et al. Nonalcoholic fatty liver in nondiabetic patients with acute coronary syndromes. Eur J Clin Invest. 2013; 43: 429-438.

4. Byrne CD, Targher G, NAFLD: a multisystem disease. J Hepatol. 2015; 62: S47-64

5. Schattenberg JM, Bergheim I. Nutritional Intake and the Risk for Non-Alcoholic Fatty Liver Disease (NAFLD. Nutrients, 2019; 11: 588.

6. Veronese N, Notarnicola M, Cisternino AM, et al. Coffee Intake and Liver Steatosis: A Population Study in a Mediterranean Area. Nutrients. 2018;10:89.

7. Jiang X, Zhang D, Jiang W. Coffee and caffeine intake and incidence of type 2 diabetes mellitus: A meta-analysis of prospective studies. Eur J Nutr 2014;53:25-38.

8. Khalaf N, White D, Kanwal F, et al. Coffee and caffeine are associated with decreased risk of advanced hepatic fibrosis among patients with hepatitis C. Clin. Gastroenterol. Hepatol. 2015;13:1521-1531.

9. Shen H, Rodriguez AC, Shiani A, et al. Association between caffeine consumption and nonalcoholic fatty liver disease: A systemic review and meta-analysis. Ther. Adv. Gastroenterol. 2016;9:113-120

10. Wadhawan M, Anand AC. Coffee and Liver Disease. J Clin Exp Hepatol. 2016;6:40-46.

11. Okamura T, Hashimoto Y, Hamaguchi M, et al. Short sleep duration is a risk of incident nonalcoholic fatty liver disease: a population-based longitudinal study. J Gastrointestin Liver Dis. 2019; 28: 73-81.

12. Bernsmeier C, Weisskopf DM, Pflueger MO, et al. Sleep disruption and daytime sleepiness correlating with disease severity and insulin resistance in non-alcoholic fatty liver disease: a comparison with healthy controls. PLoS One 2015;10:e0143293.

13. Kim D, Kim HJ, Kushida CA, Heo NY, Ahmed A, Kim WR. Short Sleep duration is associated with abnormal serum aminotransferase activities and nonalcoholic fatty liver disease. Clin Gastroenterol Hepatol 2017;16:588-590.

14. Miyake T, Kumagi T, Furukawa S, et al. Short sleep duration reduces the risk of nonalcoholic fatty liver disease onset in men: a community-based longitudinal cohort study. J Gastroenterol 2015;50:583-589.

15. Marin-Alejandre BA, Abete I, Cantero I, et al. Association between sleep disturbances and liver status in obese subjects with nonalcoholic fatty liver disease: a comparison with healthy controls. Nutrients. 2019;11:322.

16. Hamabe A, Uto H, Imamura $\mathrm{Y}$, et al. Impact of cigarette smoking on onset of nonalcoholic fatty liver disease over a 10-year period. J Gastroenterol. 2011; 46:769-778.

17. Xiong M, Li J, Yang S, et al. Impacts of cigarette smoking on liver fibrosis and its regression under therapy in male patients with chronic hepatitis B. Liver Int. 2019;39:1428-1436.

18. Hongjie O, Yaojie F, Wei L, Caixia Z, Xiaolu W, Association between smoking and liver fibrosis among patients with nonalcoholic fatty liver disease. Can J Gastroenterol Hepatol. 2019; 2019: 6028952 .

19. Sasso M, Beaugrand M, de Ledinghen V, et al. Controlled attenuation parameter (CAP): a novel VCTE guided ultrasonic attenuation measurement for the evaluation of hepatic steatosis: preliminary study and validation in a cohort of patients with chronic liver disease from various causes. Ultrasound 
Med Biol. 2010;36:1825-35.

20. Wong VW, Vergniol J, Wong GL et al. Diagnosis of fibrosis and cirrhosis using liver stiffness measurement in nonalcoholic fatty liver disease. Hepatology 2010; 51: 454-62.

21. Wong VW, Vergniol J, Wong GL et al. Liver stiffness measurement using XL probe in patients with nonalcoholic fatty liver disease. Am. J. Gastroenterol. 2012; 107: 1862-71.

22. Hamaguchi M, Kojima T, Itoh Y, et al. The severity of ultrasonographic findings in nonalcoholic fatty liver disease reflects the metabolic syndrome and visceral fat accumulation. Am J Gastroenterol 2007;102:2708-2715.

23. Marin-Alejandre BA, Abete I, Cantero I, et al. Association between Sleep Disturbances and Liver Status in Obese Subjects with Nonalcoholic Fatty Liver Disease: A Comparison with Healthy Controls. Nutrients. 2019;11:322.

24. Nordestgaard AT, Thomsen M, Nordestgaard BG. Coffee intake and risk of obesity, metabolic syndrome and type 2 diabetes: a Mendelian randomization study. Int J Epidemiol. 2015;44:551-565.

25. Shang F, Li X, Jiang X. Coffee consumption and risk of the metabolic syndrome: A meta-analysis. Diabetes Metab. 2016;42:80-87.

26. Xie C, Cui L, Zhu J, Wang K, Sun N, Sun C. Coffee consumption and risk of hypertension: a systematic review and dose-response meta-analysis of cohort studies. J Hum Hypertens. 2018;32:83-93.

27. Arnesen E, Huseby NE, Brenn T, et al. The Tromso heart study: distribution of, and determinants for, gamma-glutamyltransferase in a free-living population. Scand J Clin Lab Invest 1986;46:63-70.

28. Casiglia E, Spolaore P, Ginocchio G, et al.. Unexpected effects of coffee consumption on liver enzymes. Eur J Epidemiol. 1993;9:293-297.

29. Urgert R, Meyboom S, Kuilman M, et al. Comparison of effect of cafetiere and filtered coffee on serum concentrations of liver aminotransferases and lipids: six month randomized controlled trial. BMJ 1996;313:1362-6.

30. Honjo S, Kono S, Ogawa S, et al. Coffee consumption and serum aminotransferases in middle-aged Japanese men. J Clin Epidemiol 2001;54:823-9.

31. Wadhawan M, Anand AC. Coffee and Liver Disease. J Clin Exp Hepatol. 2016;6:40-6.

32. Birerdinc A, Stepanova M, Pawloski L, Younossi ZM. Caffeine is protective in patients with nonalcoholic fatty liver disease. Aliment Pharmacol Ther. 2012;35:76-82.

33. Catalano D, Martines GF, Tonzuso A, Pirri C, Trovato FM, Trovato GM. Protective role of coffee in non-alcoholic fatty liver disease (NAFLD). Dig Dis Sci. 2010;55:3200-3206

34. Molloy JW, Calcagno CJ, Williams CD, Jones FJ, Torres DM, Harrison SA. Association of coffee and caffeine consumption with fatty liver disease, nonalcoholic steatohepatitis, and degree of hepatic fibrosis. Hepatology. 2012;55:429-436.

35. Alferink LJM, Fittipaldi J, Kiefte-de Jong JC, et al. Coffee and herbal tea consumption is associated with lower liver stiffness in the general population: The Rotterdam study. J Hepatol. 2017;67:339-348.

36. Hodge A, Lim S, Goh E, et al. Coffee intake is associated with a lower liver stiffness in patients with non-alcoholic fatty liver disease, hepatitis C, and hepatitis B. Nutrients. 2017;9:56.

37. Arauz J, Zarco N, Segovia J, Shibayama M, Tsutsumi V, Muriel P. Caffeine prevents experimental liver fibrosis by blocking the expression of TGF- $\beta$. Eur J Gastroenterol Hepatol. 2014;26:164-173.

38. Furtado KS, Prado MG, Aguiar E Silva MA, et al. Coffee and caffeine protect against liver injury induced by thioacetamide in male Wistar rats. Basic Clin Pharmacol Toxicol. 2012;111:339-347.

39. Esposito F, Morisco F, Verde V, et al. Moderate coffee consumption increases plasma glutathione but not homocysteine in healthy subjects. Aliment Pharmacol Ther. 2003;17:595-601

40. Rodriguez de Sotillo DV, Hadley M, Sotillo JE. Insulin receptor exon 11+/- is expressed in Zucker (fa/fa) rats, and chlorogenic acid modifies their plasma insulin and liver protein and DNA. J Nutr Biochem 2006;17:63-71.

41. Prather AA, Marsland AL, Hall M, Neumann SA, Muldoon MF, Manuck SB. Normative variation in self-reported sleep quality and sleep debt is associated with stimulated pro-inflammatory cytokine production.Biol Psychol 2009;82:12-17.

42. Kern PA, Ranganathan S, Li C, Wood L, Ranganathan G. Adipose tissue tumor necrosis factor and 
interleukin-6 expression in human obesity and insulin resistance. Am J Physiol Metab 2001;280:E745E751.

43. Imai S, Kajiyama S, Hashimoto Y, et al. Divided consumption of latenight- dinner improves glycemic excursions in patients with type 2 diabetes: A randomized cross-over clinical trial. Diabetes Res Clin Pract 2017;129:206-212.

44. Itani O, Kaneita Y, Murata A, Yokoyama E, Ohida T. Association of onset of obesity with sleep duration and shift work among Japanese adults. Sleep Med 2011;12:341-345.

45. Targher G, Bertolini L, Rodella S, et al. Associations between liver histology and cortisol secretion in subjects with nonalcoholic fatty liver disease. Clin Endocrinol (Oxf). 2006; 64:337-341

46. Peng K, Lin L, Wang Z, et al. Short sleep duration and longer daytime napping are associated with non-alcoholic fatty liver disease in Chinese adults. J Diabetes. 2017;9:827-836.

47. Saadeh S, Younossi ZM, Remer EM, et al. The utility of radiological imaging in nonalcoholic fatty liver disease. Gastroenterology 2002;123:745-50.

48. Jung HS, Chang Y, Kwon MJ, et al. Smoking and the risk of non-alcoholic fatty liver disease: a cohort study. Am J Gastroenterol. 2019;114:453-463.

49. Ou H, Fu Y, Liao W, Zheng C, Wu X. Association between smoking and liver fibrosis among patients with nonalcoholic fatty liver disease. Can J Gastroenterol Hepatol. Can J Gastroenterol Hepatol. 2019;2019:6028952.

50. Eddowes PJ, Sasso M, Allison M, Tsochatzis E, Anstee QM, Sheridan D, et al. Accuracy of FibroScan controlled attenuation parameter and liver stiffness measurement in assessing steatosis and fibrosis in patients with nonalcoholic fatty liver disease. Gastroenterology. 2019;156:1717-1730.

Table 1. Demographic and laboratory characteristics of study subjects by coffee consumption, sleeping hours and smoking status

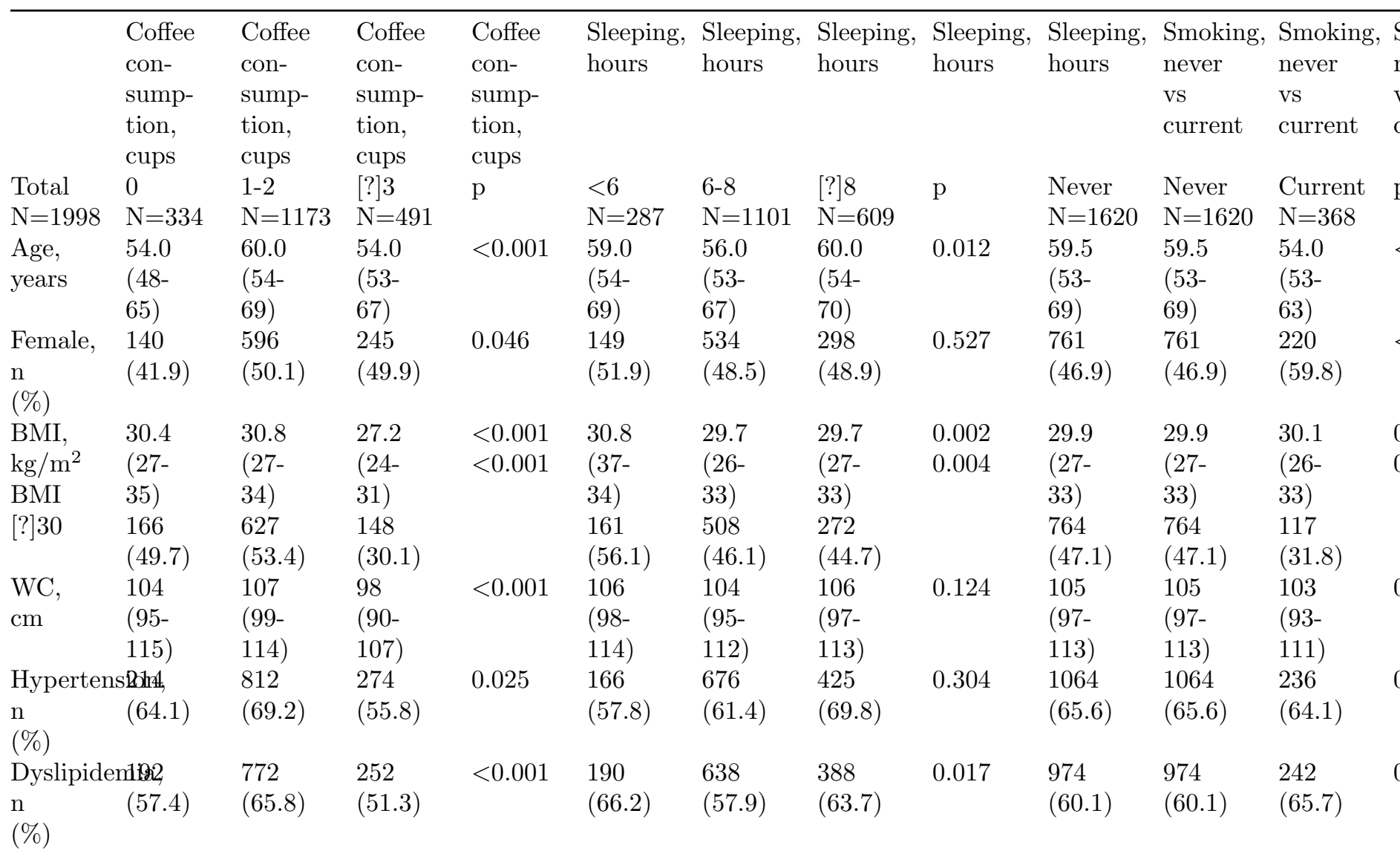




\begin{tabular}{|c|c|c|c|c|c|c|c|c|c|c|c|}
\hline $\begin{array}{l}\mathrm{DM}, \\
\mathrm{n} \\
(\%)\end{array}$ & $\begin{array}{l}113 \\
(33.8)\end{array}$ & $\begin{array}{l}491 \\
(41.8)\end{array}$ & $\begin{array}{l}123 \\
(25.0)\end{array}$ & $<0.001$ & $\begin{array}{l}152 \\
(52.9)\end{array}$ & $\begin{array}{l}316 \\
(28.7)\end{array}$ & $\begin{array}{l}259 \\
(42.5)\end{array}$ & $<0.001$ & $\begin{array}{l}580 \\
(35.8)\end{array}$ & $\begin{array}{l}580 \\
(35.8)\end{array}$ & $\begin{array}{l}174 \\
(47.2)\end{array}$ \\
\hline $\begin{array}{l}\text { Glucose, } \\
\mathrm{mmol} / \mathrm{L}\end{array}$ & $\begin{array}{l}5.7 \\
(5-7)\end{array}$ & $\begin{array}{l}6.1 \\
(5-8)\end{array}$ & $\begin{array}{l}5.5 \\
(5-7)\end{array}$ & $<0.001$ & $\begin{array}{l}6.5 \\
(5-8)\end{array}$ & $\begin{array}{l}5.7 \\
(5-7)\end{array}$ & $\begin{array}{l}6.0 \\
(5-8)\end{array}$ & $<0.001$ & $\begin{array}{l}5.8 \\
(5-7)\end{array}$ & $\begin{array}{l}5.8 \\
(5-7)\end{array}$ & $\begin{array}{l}6.0 \\
(5-8)\end{array}$ \\
\hline $\begin{array}{l}\mathrm{AST}, \\
\mathrm{U} / \mathrm{L}\end{array}$ & $\begin{array}{l}25 \\
(19- \\
34)\end{array}$ & $\begin{array}{l}22 \\
(17- \\
28)\end{array}$ & $\begin{array}{l}22 \\
(17- \\
26)\end{array}$ & $<0.001$ & $\begin{array}{l}23 \\
(18- \\
31)\end{array}$ & $\begin{array}{l}22 \\
(18- \\
29)\end{array}$ & $\begin{array}{l}22 \\
(17- \\
28)\end{array}$ & 0.119 & $\begin{array}{l}22 \\
(18- \\
29)\end{array}$ & $\begin{array}{l}22 \\
(18- \\
29)\end{array}$ & $\begin{array}{l}20 \\
(17- \\
27)\end{array}$ \\
\hline $\begin{array}{l}\text { ALT, } \\
\text { U/L }\end{array}$ & $\begin{array}{l}34 \\
(22- \\
61)\end{array}$ & $\begin{array}{l}26 \\
(20- \\
41)\end{array}$ & $\begin{array}{l}22 \\
(18- \\
32)\end{array}$ & $<0.001$ & $\begin{array}{l}30 \\
(22- \\
55)\end{array}$ & $\begin{array}{l}24 \\
(19- \\
37)\end{array}$ & $\begin{array}{l}27 \\
(20- \\
45)\end{array}$ & $<0.001$ & $\begin{array}{l}26 \\
(20- \\
41)\end{array}$ & $\begin{array}{l}26 \\
(20- \\
41)\end{array}$ & $\begin{array}{l}25 \\
(19- \\
43)\end{array}$ \\
\hline $\begin{array}{l}\text { GGT, } \\
\mathrm{U} / \mathrm{L}\end{array}$ & $\begin{array}{l}54 \\
(28- \\
80)\end{array}$ & $\begin{array}{l}31 \\
(19- \\
66)\end{array}$ & $\begin{array}{l}24 \\
(17- \\
44)\end{array}$ & $<0.001$ & $\begin{array}{l}34 \\
(19- \\
66)\end{array}$ & $\begin{array}{l}31 \\
(20- \\
66)\end{array}$ & $\begin{array}{l}32 \\
(20- \\
70)\end{array}$ & 0.260 & $\begin{array}{l}32 \\
(20- \\
66)\end{array}$ & $\begin{array}{l}32 \\
(20- \\
66)\end{array}$ & $\begin{array}{l}31 \\
(18- \\
67)\end{array}$ \\
\hline $\begin{array}{l}\text { Cholester } \\
\mathrm{mmol} / \mathrm{L}\end{array}$ & $\begin{array}{l}0 \$, 2 \\
(4-6)\end{array}$ & $\begin{array}{l}5.2 \\
(4-6)\end{array}$ & $\begin{array}{l}5.1 \\
(4-6)\end{array}$ & 0.827 & $\begin{array}{l}4.9 \\
(4-5)\end{array}$ & $\begin{array}{l}5.3 \\
(4-6)\end{array}$ & $\begin{array}{l}5.0 \\
(4-6)\end{array}$ & $<0.001$ & $\begin{array}{l}5.0 \\
(4-6)\end{array}$ & $\begin{array}{l}5.0 \\
(4-6)\end{array}$ & $\begin{array}{l}5.5 \\
(5-7)\end{array}$ \\
\hline $\begin{array}{l}\mathrm{HDL}, \\
\mathrm{mmol} / \mathrm{L}\end{array}$ & $\begin{array}{l}1.3 \\
(1- \\
1.5)\end{array}$ & $\begin{array}{l}1.3 \\
(1- \\
1.5)\end{array}$ & $\begin{array}{l}1.5 \\
(1- \\
1.7)\end{array}$ & $<0.001$ & $\begin{array}{l}1.3 \\
(1- \\
1.5)\end{array}$ & $\begin{array}{l}1.4 \\
(1- \\
1.6)\end{array}$ & $\begin{array}{l}1.2 \\
(1- \\
1.4)\end{array}$ & $<0.001$ & $\begin{array}{l}1.3 \\
(1- \\
1.6)\end{array}$ & $\begin{array}{l}1.3 \\
(1- \\
1.6)\end{array}$ & $\begin{array}{l}1.4 \\
(1- \\
1.6)\end{array}$ \\
\hline $\begin{array}{l}\mathrm{LDL}, \\
\mathrm{mmol} / \mathrm{L}\end{array}$ & $\begin{array}{l}2.9 \\
(2- \\
3.9)\end{array}$ & $\begin{array}{l}2.9 \\
(2- \\
3.8)\end{array}$ & $\begin{array}{l}2.9 \\
(2- \\
3.6)\end{array}$ & 0.633 & $\begin{array}{l}2.7 \\
(2- \\
3.6)\end{array}$ & $\begin{array}{l}3.0 \\
(2- \\
3.9)\end{array}$ & $\begin{array}{l}2.8 \\
(2- \\
3.7)\end{array}$ & 0.002 & $\begin{array}{l}2.8 \\
(2- \\
3.7)\end{array}$ & $\begin{array}{l}2.8 \\
(2- \\
3.7)\end{array}$ & $\begin{array}{l}3.1 \\
(2.4- \\
4)\end{array}$ \\
\hline $\begin{array}{l}\mathrm{TG}, \\
\mathrm{mmol} / \mathrm{L}\end{array}$ & $\begin{array}{l}1.6 \\
(1- \\
2.2)\end{array}$ & $\begin{array}{l}1.6 \\
(1- \\
2.3)\end{array}$ & $\begin{array}{l}1.3 \\
(0.9- \\
2)\end{array}$ & $<0.001$ & $\begin{array}{l}1.6 \\
(1- \\
2.4)\end{array}$ & $\begin{array}{l}1.5 \\
(1- \\
2.5)\end{array}$ & $\begin{array}{l}1.6 \\
(1- \\
2.3)\end{array}$ & $<0.001$ & $\begin{array}{l}1.5 \\
(1- \\
2.1)\end{array}$ & $\begin{array}{l}1.5 \\
(1- \\
2.1)\end{array}$ & $\begin{array}{l}1.7 \\
(1- \\
2.4)\end{array}$ \\
\hline $\begin{array}{l}\text { HOMA- } \\
\text { IR } \\
\text { score }\end{array}$ & $\begin{array}{l}3.8 \\
(2-6)\end{array}$ & $\begin{array}{l}4.5 \\
(3-7)\end{array}$ & $\begin{array}{l}2.7 \\
(2-4)\end{array}$ & $<0.001$ & $\begin{array}{l}4.6 \\
(2-7)\end{array}$ & $\begin{array}{l}3.7 \\
(2.6)\end{array}$ & $\begin{array}{l}4.3 \\
(3-7)\end{array}$ & $<0.001$ & $\begin{array}{l}4.1 \\
(2-6)\end{array}$ & $\begin{array}{l}4.1 \\
(2-6)\end{array}$ & $\begin{array}{l}3.7 \\
(2.6)\end{array}$ \\
\hline $\begin{array}{l}\text { Urati, } \\
\mathrm{mmol} / \mathrm{L}\end{array}$ & $\begin{array}{l}349 \\
(286- \\
407)\end{array}$ & $\begin{array}{l}342 \\
(284- \\
412)\end{array}$ & $\begin{array}{l}314 \\
(252- \\
379)\end{array}$ & $<0.001$ & $\begin{array}{l}332 \\
(281- \\
404)\end{array}$ & $\begin{array}{l}335 \\
(266- \\
405)\end{array}$ & $\begin{array}{l}342 \\
(285- \\
406)\end{array}$ & 0.187 & $\begin{array}{l}339 \\
(279- \\
407)\end{array}$ & $\begin{array}{l}339 \\
(279- \\
407)\end{array}$ & $\begin{array}{l}326 \\
(276- \\
392)\end{array}$ \\
\hline $\begin{array}{l}\text { Vitamin } \\
\mathrm{D}, \\
\mathrm{nmol} / \mathrm{L}\end{array}$ & $\begin{array}{l}62.3 \\
(39- \\
84)\end{array}$ & $\begin{array}{l}59.4 \\
(43- \\
79)\end{array}$ & $\begin{array}{l}62.4 \\
(42- \\
83)\end{array}$ & 0.507 & $\begin{array}{l}60.8 \\
(45- \\
83)\end{array}$ & $\begin{array}{l}61.5 \\
(43- \\
82)\end{array}$ & $\begin{array}{l}57.4 \\
(39- \\
77)\end{array}$ & 0.006 & $\begin{array}{l}61.5 \\
(43- \\
82)\end{array}$ & $\begin{array}{l}61.5 \\
(43- \\
82)\end{array}$ & $\begin{array}{l}55.1 \\
(39- \\
77)\end{array}$ \\
\hline $\begin{array}{l}\mathrm{CRP} \\
\mathrm{mg} / \mathrm{L}\end{array}$ & $\begin{array}{l}2.6 \\
(1.3- \\
5)\end{array}$ & $\begin{array}{l}2.3 \\
(1.2- \\
4)\end{array}$ & $\begin{array}{l}2.0 \\
(0.9- \\
4)\end{array}$ & 0.005 & $\begin{array}{l}2.5 \\
(1.2- \\
4)\end{array}$ & $\begin{array}{l}2.2 \\
(1- \\
4.2)\end{array}$ & $\begin{array}{l}2.3 \\
(1- \\
4.8)\end{array}$ & 0.151 & $\begin{array}{l}2.3 \\
(1-4)\end{array}$ & $\begin{array}{l}2.3 \\
(1-4)\end{array}$ & $\begin{array}{l}2.4 \\
(1-5)\end{array}$ \\
\hline $\begin{array}{l}\mathrm{CAP} \\
\mathrm{dB} / \mathrm{m}\end{array}$ & $\begin{array}{l}328 \\
(294- \\
352)\end{array}$ & $\begin{array}{l}310 \\
(275- \\
345)\end{array}$ & $\begin{array}{l}224 \\
(210- \\
246)\end{array}$ & $<0.001$ & $\begin{array}{l}308 \\
(273- \\
344)\end{array}$ & $\begin{array}{l}289 \\
(243- \\
334)\end{array}$ & $\begin{array}{l}299 \\
(252- \\
336)\end{array}$ & $<0.001$ & $\begin{array}{l}297 \\
(253- \\
338)\end{array}$ & $\begin{array}{l}297 \\
(253- \\
338)\end{array}$ & $\begin{array}{l}290 \\
(245- \\
335)\end{array}$ \\
\hline $\begin{array}{l}\mathrm{LSM}, \\
\mathrm{kPa}\end{array}$ & $\begin{array}{l}5.4 \\
(4.4- \\
7.0)\end{array}$ & $\begin{array}{l}5.3 \\
(4.3- \\
6.8)\end{array}$ & $\begin{array}{l}4.7 \\
(3.7- \\
6.0)\end{array}$ & $<0.001$ & $\begin{array}{l}5.1 \\
(4.3- \\
6.7)\end{array}$ & $\begin{array}{l}4.9 \\
(4.0- \\
6.3)\end{array}$ & $\begin{array}{l}5.3 \\
(4.2- \\
7.0)\end{array}$ & $<0.001$ & $\begin{array}{l}5.1 \\
(4.1- \\
6.7)\end{array}$ & $\begin{array}{l}5.1 \\
(4.1- \\
6.7)\end{array}$ & $\begin{array}{l}5.1 \\
(4.1- \\
6.4)\end{array}$ \\
\hline
\end{tabular}

*body mass index (BMI); waist circumference (WC); diabetes mellitus type II (DM); aspartate aminotransferase (AST); alanine aminotransferase (ALT); gamma glutamyl transferase (GGT); high-density lipoprotein (HDL); low-density lipoprotein (LDL); triglycerides (TG), homeostasis model assessment - insulin resistance (HOMA-IR); C-reactive protein (CRP); controlled attenuation parameter (CAP); liver stiffness measurement (LSM)

Table 2. Association of coffee consumption with demographical data, laboratory values and elastographic 
parameters

\begin{tabular}{|c|c|c|c|c|}
\hline & 0 cups vs [?]3 cups per day & 0 cups vs [?]3 cups per day & 0 cups vs [?]3 cups per day & 0 cups vs [ \\
\hline & Univariate & Univariate & Multivariate & Multivariat \\
\hline & OR $(95 \% \mathrm{CI})$ & $\mathrm{p}$ value & OR $(95 \% \mathrm{CI})$ & $\mathrm{p}$ value \\
\hline Age, years & $1.01(0.99-1.03)$ & 0.063 & & \\
\hline Gender (female) & $1.38(1.04-1.83)$ & 0.022 & & \\
\hline $\mathrm{BMI}, \mathrm{kg} / \mathrm{m}^{2}$ & $0.87(0.84-0.89)$ & $<0.001$ & & \\
\hline BMI [?] $30 \mathrm{~kg} / \mathrm{m}^{2}$ & $0.43(0.32-0.58)$ & $<0.001$ & $0.13(0.01-1.38)$ & 0.091 \\
\hline $\mathrm{WC}, \mathrm{cm}$ & $0.96(0.95-0.98)$ & $<0.001$ & $0.89(0.85-0.98)$ & 0.021 \\
\hline Hypertension, n (\%) & $0.76(0.55-1.04)$ & 0.097 & & \\
\hline Dyslipidemia, n (\%) & $0.85(0.63-1.15)$ & 0.307 & & \\
\hline DM, n $(\%)$ & $0.68(0.50-0.94)$ & 0.018 & & \\
\hline Glucose, mmol/L & $0.99(0.94-1.03)$ & 0.691 & & \\
\hline AST, U/L & $0.97(0.95-0.98)$ & $<0.001$ & & \\
\hline ALT, U/L & $0.98(0.97-0.99)$ & $<0.001$ & $0.94(0.90-0.97)$ & 0.030 \\
\hline GGT, U/L & $0.98(0.97-0.99)$ & $<0.001$ & $0.96(0.94-0.98)$ & $<0.001$ \\
\hline Cholesterol, mmol/L & $0.99(0.97-1.02)$ & 0.981 & & \\
\hline HDL, mmol/L & $2.76(1.64-4.64)$ & $<0.001$ & & \\
\hline $\mathrm{LDL}, \mathrm{mmol} / \mathrm{L}$ & $0.90(0.77-1.05)$ & 0.198 & & \\
\hline $\mathrm{TG}, \mathrm{mmol} / \mathrm{L}$ & $0.99(0.96-1.03)$ & 0.821 & & \\
\hline HOMA-IR score & $0.91(0.87-0.96)$ & $<0.001$ & & \\
\hline Urati, mmol/L & $0.98(0.97-0.99)$ & 0.002 & & \\
\hline Vitamin D, nmol/L & $1.01(0.99-1.02)$ & 0.490 & & \\
\hline $\mathrm{CRP}, \mathrm{mg} / \mathrm{L}$ & $1.01(0.99-1.02)$ & 0.540 & & \\
\hline $\mathrm{CAP}, \mathrm{dB} / \mathrm{m}$ & $0.95(0.94-0.96)$ & $<0.001$ & $0.92(0.829-0.95)$ & $<0.001$ \\
\hline LSM, kPa & $0.81(0.77-0.86)$ & $<0.001$ & & \\
\hline
\end{tabular}

*Analysis was adjusted for age and gender.

**body mass index (BMI); waist circumference (WC); diabetes mellitus type II (DM); aspartate aminotransferase (AST); alanine aminotransferase (ALT); gamma glutamyl transferase (GGT); high-density lipoprotein (HDL); low-density lipoprotein (LDL); triglycerides (TG), homeostasis model assessment - insulin resistance (HOMA-IR); C-reactive protein (CRP); controlled attenuation parameter (CAP); liver stiffness measurement (LSM); odds ration (OR); confidence interval $(\mathrm{Cl})$

Table 3. Association of sleeping hours with demographical data, laboratory values and elastographic parameters

\begin{tabular}{|c|c|c|c|c|c|c|}
\hline & Sleeping, hours & Sleeping, hours & Sleeping, hours & Sleeping, hours & Sleeping, hours & Sleeping, \\
\hline & {$[?] 8$ vs $<6$} & {$[?] 8$ vs $<6$} & {$[?] 8$ vs $<6$} & {$[?] 8$ vs $<6$} & {$[?] 8$ vs $<6$} & {$[?] 8$ vs $6-\varepsilon$} \\
\hline & Univariate & Univariate & Multivariate & Multivariate & Multivariate & Univariat \\
\hline & OR $(95 \% \mathrm{CI})$ & $\mathrm{p}$ value & OR $(95 \% \mathrm{CI})$ & $\mathrm{p}$ value & OR $(95 \% \mathrm{CI})$ & OR $(95 \%$ \\
\hline Age, years & $0.99(0.98-1.01)$ & 0.703 & & & $0.98(0.97-0.99)$ & $0.98(0.97$ \\
\hline Gender (female) & $1.12(0.85-1.49)$ & 0.404 & & & $0.98(0.80-1.19)$ & $0.98(0.80$ \\
\hline $\mathrm{BMI}, \mathrm{kg} / \mathrm{m}^{2}$ & $1.03(0.99-1.05)$ & 0.053 & & & $1.01(0.99-1.03)$ & $1.01(0.99$ \\
\hline BMI [?] $30 \mathrm{~kg} / \mathrm{m}^{2}$ & $1.58(1.19-2.10)$ & 0.001 & & & $1.06(0.86-1.29)$ & $1.06(0.86$ \\
\hline $\mathrm{WC}, \mathrm{cm}$ & $1.01(0.99-1.02)$ & 0.512 & & & $1.01(0.99-1.01)$ & $1.01(0.99$ \\
\hline Hypertension, n (\%) & $1.01(0.71-1.40)$ & 0.994 & & & $0.67(0.53-0.85)$ & $0.67(0.53$ \\
\hline Dyslipidemia, n (\%) & $1.14(0.82-1.57)$ & 0.416 & & & $0.79(0.63-0.98)$ & $0.79(0.63$ \\
\hline DM, n $(\%)$ & $1.59(1.18-2.13)$ & 0.002 & & & $0.54(0.43-0.66)$ & $0.54(0.43$ \\
\hline
\end{tabular}




\begin{tabular}{lllllll}
\hline & Sleeping, hours & Sleeping, hours & Sleeping, hours & Sleeping, hours & Sleeping, hours & Sleeping, \\
\hline Glucose, mmol/L & $1.08(1.01-1.14)$ & 0.001 & & & $1.05(0.99-1.02)$ & $1.05(0.99$ \\
AST, U/L & $1.02(1.01-1.03)$ & 0.032 & & & $1.01(0.99-1.01)$ & $1.01(0.99$ \\
ALT, U/L & $1.02(1.01-1.03)$ & 0.034 & & $1.02(1.01-1.03)$ & $1.02(1.01$ \\
GGT, U/L & $1.01(0.99-1.02)$ & 0.574 & & $0.99(0.98-1.01)$ & $0.99(0.98$ \\
Cholesterol, mmol/L & $0.96(0.87-1.05)$ & 0.429 & & $1.02(0.98-1.07)$ & $1.02(0.98$ \\
HDL, mmol/L & $1.26(0.78-2.04)$ & 0.336 & & & $2.11(1.47-3.01)$ & $2.11(1.47$ \\
LDL, mmol/L & $0.92(0.78-1.08)$ & 0.312 & & & $1.17(1.04-1.31)$ & $1.17(1.04$ \\
TG, mmol/L & $0.94(0.85-1.04)$ & 0.290 & & $0.99(0.97-1.01)$ & $0.99(0.97$ \\
HOMA-IR score & $1.01(0.98-1.02)$ & 0.764 & & $0.95(0.93-0.98)$ & $0.95(0.93$ \\
Urati, mmol/L & $1.01(0.99-1.02)$ & 0.897 & & $0.99(0.98-1.01)$ & $0.99(0.98$ \\
Vitamin D, nmol/L & $1.02(1.01-1.04)$ & 0.012 & & & $1.01(1.00-1.02)$ & $1.01(1.00$ \\
CRP, mg/L & $1.01(0.97-1.01)$ & 0.418 & & & $1.01(0.99-1.02)$ & $1.01(0.99$ \\
CAP, dB/m & $1.02(1.01-1.03)$ & $<0.001$ & & & $0.98(0.97-0.99)$ & $0.98(0.97$ \\
LSM, $\mathrm{kPa}$ & $0.94(0.90-0.99)$ & 0.041 & & & $0.93(0.90-0.96)$ & $0.93(0.90$ \\
\hline
\end{tabular}

*Analysis was adjusted for age and gender.

****body mass index (BMI); waist circumference (WC); diabetes mellitus type II (DM); aspartate aminotransferase (AST); alanine aminotransferase (ALT); gamma glutamyl transferase (GGT); high-density lipoprotein (HDL); low-density lipoprotein (LDL); triglycerides (TG), homeostasis model assessment - insulin resistance (HOMA-IR); C-reactive protein (CRP); controlled attenuation parameter (CAP); liver stiffness measurement (LSM); odds ratio (OR); confidence interval $(\mathrm{Cl})$

Table 4. Association of smoking status with demographical data, laboratory values and elastography parameters LSM and CAP

\begin{tabular}{|c|c|c|c|c|}
\hline & Smoking & Smoking & Smoking & Smoking \\
\hline & $\begin{array}{l}\text { never vs current } \\
\text { Univariate }\end{array}$ & never vs current & $\begin{array}{l}\text { never vs current } \\
\text { Multivariate }\end{array}$ & never vs current \\
\hline & OR $(95 \% \mathrm{CI})$ & $\mathrm{p}$ value & OR $(95 \%$ CI $)$ & $\mathrm{p}$ value \\
\hline Age, years & $0.97(0.96-0.98)$ & $<0.001$ & $0.97(0.95-0.98)$ & 0.001 \\
\hline Gender (female) & $1.58(1.26-1.98)$ & $<0.001$ & $1.62(1.14-2.28)$ & 0.006 \\
\hline $\mathrm{BMI}, \mathrm{kg} / \mathrm{m}^{2}$ & $0.98(0.96-1.01)$ & 0.276 & & \\
\hline BMI [?] $30 \mathrm{~kg} / \mathrm{m}^{2}$ & $0.99(0.79-1.24)$ & 0.941 & & \\
\hline $\mathrm{WC}, \mathrm{cm}$ & $0.98(0.97-1.01)$ & 0.065 & & \\
\hline Hypertension, n (\%) & $0.82(0.64-1.06)$ & 0.146 & & \\
\hline Dyslipidemia, n (\%) & $1.18(0.92-1.52)$ & 0.179 & & \\
\hline $\mathrm{DM}, \mathrm{n}(\%)$ & $1.13(0.89-1.43)$ & 0.291 & & \\
\hline Glucose, $\mathrm{mmol} / \mathrm{L}$ & $0.99(0.98-1.01)$ & 0.649 & & \\
\hline $\mathrm{AST}, \mathrm{U} / \mathrm{L}$ & $0.99(0.98-1.01)$ & 0.290 & & \\
\hline ALT, U/L & $0.99(0.98-1.01)$ & 0.512 & & \\
\hline GGT, U/L & $1.02(1.01-1.03)$ & 0.012 & & \\
\hline Cholesterol, mmol/L & $1.02(1.01-1.03)$ & 0.043 & & \\
\hline HDL, mmol/L & $0.97(0.88-1.07)$ & 0.644 & & \\
\hline $\mathrm{LDL}, \mathrm{mmol} / \mathrm{L}$ & $0.99(0.97-1.02)$ & 0.909 & & \\
\hline $\mathrm{TG}, \mathrm{mmol} / \mathrm{L}$ & $1.01(0.99-1.02)$ & 0.354 & & \\
\hline HOMA-IR score & $1.01(0.98-1.02)$ & 0.569 & & \\
\hline Urates, $\mathrm{mmol} / \mathrm{L}$ & $0.98(0.97-1.02)$ & 0.192 & & \\
\hline Vitamin $\mathrm{D}, \mathrm{nmol} / \mathrm{L}$ & $0.99(0.98-1.01)$ & 0.180 & & \\
\hline CRP, mg/L & $1.01(0.99-1.02)$ & 0.204 & & \\
\hline
\end{tabular}




\begin{tabular}{lllll}
\hline & Smoking & Smoking & Smoking & Smoking \\
\hline $\mathrm{CAP}, \mathrm{dB} / \mathrm{m}$ & $0.99(0.98-1.01)$ & 0.362 & & \\
LSM, $\mathrm{kPa}$ & $0.99(0.95-1.03)$ & 0.886 & & \\
\hline
\end{tabular}

*Analysis was adjusted for age and gender

**body mass index (BMI); waist circumference (WC); diabetes mellitus type II (DM); aspartate aminotransferase (AST); alanine aminotransferase (ALT); gamma glutamyl transferase (GGT); high-density lipoprotein (HDL); low-density lipoprotein (LDL); triglycerides (TG), homeostasis model assessment - insulin resistance (HOMA-IR); C-reactive protein (CRP); controlled attenuation parameter (CAP); liver stiffness measurement (LSM); odds ratio (OR); confidence interval $(\mathrm{Cl})$

Table 5. Association between coffee consumption, sleeping hours and smoking status with CAP and LSM

\begin{tabular}{lllll}
\hline & Coffee consumption, cups & Coffee consumption, cups & Coffee consumption, cups & Coffee consumption \\
& 0 vs [?]3 & O vs [?]3 & 0 vs 1-2 & 0 vs 1-2 \\
& OR (95\% CI) & p value & OR $(95 \% \mathrm{CI})$ & p value \\
CAP, unadjusted & $0.95(0.94-0.96)$ & $<0.001$ & $0.97(0.98-0.99)$ & $<0.001$ \\
CAP, model 1 & $0.95(0.94-0.96)$ & $<0.001$ & $0.98(0.97-0.99)$ & 0.003 \\
CAP, model 2 & $0.94(0.93-0.96)$ & $<0.001$ & $0.98(0.97-0.99)$ & 0.004 \\
CAP, model 3 & $0.88(0.81-0.94)$ & $<0.001$ & $0.98(0.97-0.99)$ & $<0.001$ \\
LSM, unadjusted & $0.81(0.77-0.86)$ & $<0.001$ & $0.95(0.92-0.99)$ & 0.021 \\
LSM, model 1 & $0.84(0.78-0.91)$ & $<0.001$ & $0.96(0.91-1.01)$ & 0.194 \\
LSM, model 2 & $0.87(0.81-0.94)$ & $<0.001$ & $0.96(0.91-1.02)$ & 0.235 \\
LSM, model 3 & $0.95(0.82-1.11)$ & 0.564 & $1.01(0.93-1.11)$ & 0.6684 \\
\hline
\end{tabular}

*Model 1 - adjustment for age, gender, Model 2 - adjustment for age, gender, body mass index, waist circumference, Model 3 - adjustment for age, gender, body mass index, waist circumference, alanine aminotransferase, gamma glutamyl transferase, vitamin $\mathrm{D}$, type 2 diabetes mellitus, hypertension

** controlled attenuation parameter (CAP); liver stiffness measurement (LSM); odds ratio (OR); confidence interval $(\mathrm{Cl})$

\section{Hosted file}

Figures $1 \mathrm{kps}$.docx available at https://authorea.com/users/345083/articles/471431relationship-between-coffee-consumption-sleep-duration-and-smoking-status-withelastographic-parameters-of-liver-steatosis-and-fibrosis-controlled-attenuationparameter-and-liver-stiffness-measurements

\section{Hosted file}

Figure 2 kps.docx available at https://authorea.com/users/345083/articles/471431relationship-between-coffee-consumption-sleep-duration-and-smoking-status-withelastographic-parameters-of-liver-steatosis-and-fibrosis-controlled-attenuationparameter-and-liver-stiffness-measurements

\section{Hosted file}

Figure $3 \mathrm{kps.docx}$ available at https://authorea.com/users/345083/articles/471431relationship-between-coffee-consumption-sleep-duration-and-smoking-status-withelastographic-parameters-of-liver-steatosis-and-fibrosis-controlled-attenuationparameter-and-liver-stiffness-measurements 